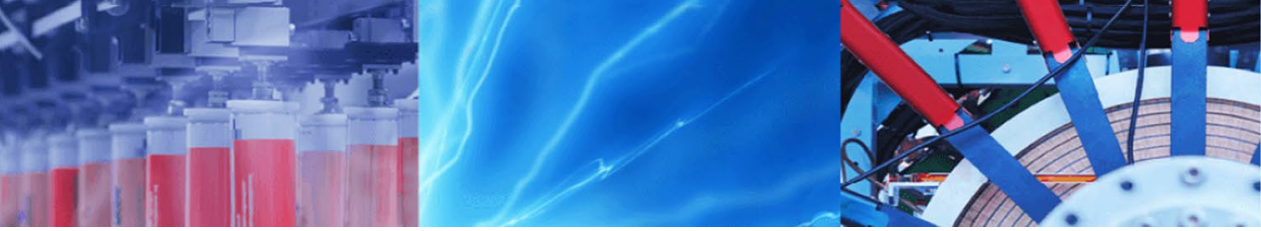

Research Article

\title{
Wear studies of composite microwave clad on martensitic stainless steel
}

\author{
Ajit M. Hebbale ${ }^{1} \cdot$ Anikethan Bekal $^{1}$ - M. S. Srinath ${ }^{2}$
}

C) Springer Nature Switzerland AG 2019

\begin{abstract}
In the present work, clads were developed through microwave energy which is as an emerging trend. Martensitic stainless steel (SS-420) is considered as a substrate material to improve its surface properties. In the present work, clad powder such as tungsten carbide and cobalt-based powders were used in the weight ratio of 1:0.12, respectively. The clads were developed using domestic microwave oven at $2.45 \mathrm{GHz}$ frequency and $900 \mathrm{~W}$ power through microwave hybrid heating technique. After performing a number of trials, the clads were developed with good metallurgical bond with an exposure time of $30 \mathrm{~min}$. The main objective of clad development is to obtain a good mechanical and tribological properties. Wear studies through pin-on-disc method of the developed clad was performed on the basis of Taguchi method (L9) orthogonal array. The main influencing factors considered are sliding distance, sliding speed and load. It is observed that the sliding distance is most dominating factor than load and sliding speed.
\end{abstract}

Keywords Microwave cladding $\cdot$ Hybrid heating $\cdot$ Wear $\cdot$ Taguchi $\cdot$ ANOVA

\section{Introduction}

Processing of materials is the important phenomenon of converting the raw materials into desired finished goods. In the present industrial standard, materials are processed by the conventional techniques and non-conventional techniques [1]. There is always a new scope in the industry for materials with improved strength, less production time and joining of dissimilar metals. Material processing through microwave energy is emerging as a new technique to fabricate alloy material and to improve the tribological properties of the material [2]. Several experiments are carried out for processing of materials through microwave energy such as sintering, joining of materials and manufacturing of alloys to overcome the limitations of the surface-related problems [3]. The desire for more strength and hard material is a major requirement in the present industries along with the enhanced mechanical, physical and chemical properties to improve wear and corrosion resistance properties. Martensitic stainless steel (SS-420) plays a very important role in increasing hardness and strength. It is generally used in hydropower plants, medical equipment, dental equipment, blades, etc. The impact force of any foreign material is common in the working field; hence, it is desired to have high impact strength on the surface of the material. To overcome the difficulties of a single material, the surface coating or cladding is very much essential $[4,5]$. Microwaves are electromagnetic waves of frequency $300 \mathrm{MHz}$ to $300 \mathrm{GHz}$ with a wavelength of $1 \mathrm{~mm}$ to $1000 \mathrm{~mm}$. The microwaves have a characteristic of volumetric heating as heating takes place at a molecular level. Initially, microwaves were used only for telecommunication and later due to the potential of new technique and research carried out it is used in food processing, processing of ceramics, etc. Presently, microwave applications in material processing are microwave sintering, microwave joining, microwave drilling, microwave cladding, microwave melting, etc. The main advantages

Ajit M. Hebbale, ajit.hebbale@gmail.com | 'Department of Mechanical Engineering, NMAM Institute of Technology, Nitte 574110, India. ${ }^{2}$ Department of Mechanical Engineering, Malnad College of Engineering, Hassan 573201, India.

SN Applied Sciences (2019) 1:196| https://doi.org/10.1007/s42452-019-0214-0

Received: 14 August 2018 / Accepted: 24 January 2019 / Published online: 1 February 2019 
of microwave processing is molecular heating of the materials, less production time and more power-efficient, dissimilar metals can be joined.

The cladding is mainly used in surface engineering applications for the improvement in the tribological behaviour of the material such as corrosion, wear and erosion resistance. Generally, cladding is a technique of coating a suitable high strength powder material onto the substrate or base material by complete melting of the powder and partial melting of the substrate, by metallurgical bonding of both the materials. The desired result can be used in various practical applications such as high corrosion or wear environment. There are several methods for cladding that include metal inert gas (MIG), shielded metal arc (SMA), tungsten inert gas (TIG), high-velocity oxy-fuel (HVOF) and laser cladding [6]. Nowadays, laser cladding is one of the popular method in industries, since it has better control over the dilution level and has high cooling rate. Faster cooling rate ensures better microstructure of the material. However, it was found that there were some limitations in this method as cracking of clad during the process, due to high thermal stress and thermal distortion (Sheng fenget al. 2008). Gupta and Sharma [5] described the experiment conducted on nickel-based EWAC clad developed on austenitic stainless steel. During the microwave heating, the volumetric heating formation of the various elements is visible with the better enhanced property. Hebbale et al. [7] reported that SS-304 is used as the substrate material and nickel powder is used as a clad powder. Microwave hybrid heating technique was used in a domestic microwave oven. The developed clad is examined in SEM, XRD and found to be with good metallurgical bonding and porosity was found to be approximately $0.87 \%$. The average Vicker's microhardness was found to be $364 \pm 70 \mathrm{HV}$. Tungsten carbide with $12 \%$ cobalt-based powder is used for this experiment. The cobalt and tungsten are used in many applications due to its high strength and wear-resistant properties at high temperature. The hardness of the alloy is mainly due to the complexity of metal carbides [8]. Usually, for the deposition of WC-Co high-velocity oxy-fuel (HVOF) technique used. HVOF uses combustion of gases, such as fuel in liquid form is thermally sprayed. This method creates high-velocity particles, these are deposited onto the substrate. HVOF coating has the main drawback of increase in porosity. In a study by Zafar and Sharma [4, 9], the abrasive and erosive wear performance of WC-12Co powder is experimented by microwave clad. The clads were developed on austenitic stainless steel as base metal, micrometric and nanometric WC-Co as a clad powder using microwave hybrid technique. The work is reported with the increase in higher erosive and abrasive wear resistance of nanometric WC-12Co clad. In the work reported by [10], a martensitic stainless steel is used as a substrate over cobalt-based powder using microwave cladding. The work is done using slurry erosive wear studies and the design of statistical approach. The influence of various factors is found using ANOVA, and the more significant factor found is speed.

The pin-on-disc wear analysis mainly depends on the effect of sliding speed, sliding distance, load, properties of the powder and the base material. Powder particles must be harder than the substrate for better tribological property. In the experiment reported by Gajjal et al. [10], the tribological behaviour of peek composites including the different amount of filler materials is analysed. The wear test is done using Taguchi, ANOVA is carried out to signify each factor of contribution to the wear. It is found out that sliding velocity and pressure play an important role in the performance of the composite material. Design of experiments (DOE) are a systematic method to determine the relationship between factors affecting a process. DOE determines the allocation and method of experiments to satisfy the objectives. Taguchi technique is a powerful tool for engineering design analysis of various factors affecting the experiment. This technique reduces the number of experiments to be conducted there by directly reducing cost and time. This technique uses orthogonal arrays based on the level or factors to plan the process, and results are based on average analysis and ANOVA [11]. Bushroa et al. [12] used Taguchi method to check the various factors like load, density and sliding speed on the friction function of texture tungsten carbide cemented carbide.

The author $[4,13]$ further studied about the erosive and abrasive wear performance of the WC-12Co microwave clads of austenitic stainless steel substrate through microwave hybrid heating technique. The micrometric clads exhibited the occurrence of uniformly distributed skeleton-like structured carbides in the metallic matrix. On the contrary, the occurrence of clusters of nanocarbides was seen in the nanometric WC-12Co clads. SEM images of micrometric and nanometric WC-12Co-based clad. It was also observed that average Vicker's microhardness of nanometric clad $(1564 \pm 53 \mathrm{Hv})$ was about 1.37 times higher than the micrometric clad $(1138 \pm 90 \mathrm{Hv})$. Nanometric clads exhibited around 54\% higher wear resistance than the micrometric clads. Three-body abrasive wear test was carried out using a dry sand rubber wheel apparatus. The erosive wear performance was carried out with different loads $(30,60$ and $90 \mathrm{~N})$ and impact angles $\left(30^{\circ}, 60^{\circ}\right.$ and $90^{\circ}$ ) using solid particle erosion with alumina as erodent. Higher microhardness and improved volume fraction lead to superior abrasive wear resistance of the WC-12Co and nanometric clads.

It was found that the area density plays an important role in the mean coefficient and wear rate. However, it is observed that there is not much work reported in the 
literature, on wear study of WC-12Co clad on SS-420 substrate using microwave cladding process. The statistical and control factor analysis by ANOVA technique is used to evaluate the most dominated factor and individual contribution of factors to wear.

\section{Experimentation}

\subsection{Microwave cladding}

The present investigation deals with tungsten carbide and 12 weight $\%$ of cobalt-based powder and SS-420 as substrate. The powder material has more strength and resistance to wear and corrosion. Cladding is done in the domestic microwave apparatus on martensitic stainless steel. The following sections will describe the process.

\subsubsection{Material details}

The WC-12Co has high hardness and toughness and the most popular wear-resistant materials used in various applications. The substrate was machined using a slow diamond cutter to the fine size of $14 \mathrm{~mm} \times 12 \mathrm{~mm} \times 5 \mathrm{~mm}$. The WC-12Co powder is examined (SEM, EDS, XRD) prior to cladding. The chemical composition of the substrate is given in Table 1.

\subsubsection{Development of clad}

Preparation of raw material is critical in the cladding process, and initially tungsten carbide and cobalt-based powder are taken in the weight percentage of $88 \mathrm{~g}$ and $12 \mathrm{~g}$, respectively. The powder mixture is mixed with resin, prepared in paste form and then applied on the substrate material in approximately uniform thickness. To develop clads, several experiments are carried out on the domestic multimode microwave oven of frequency $2.45 \mathrm{GHz}$.

The main limitations of the microwave heating of metals are because of the following two factors:

(a) At room temperature, the microwave absorption coefficient is less for metals [14]

(b) Thermal instabilities can lead to the thermal runaway [15].

The absorption is targeted by a new method of heating called microwave hybrid heating $(\mathrm{MHH})$. Microwave hybrid heating technique is used for the process of melting the metal powders with low absorption coefficient. In this technique, both conventional heating through conduction and microwave heating of material take place. Usually, in this method the susceptor materials are used to absorb microwave energy. The susceptor is a material that absorbs the microwave energy at room temperature and converts into heat energy. The susceptor materials are silicon carbide, graphite, charcoal, etc. The susceptor is placed on top of the clad powder, it absorbs the microwave energy and converts to heat energy and conduction takes place. For avoiding the contamination of the susceptor and clad powder, a thin layer of the separator (glass wool) is placed in between them. To minimise the loss of heat from the refractory material, charcoal powders are covered around the substrate. The setup is enclosed in a refractory material (aluminium oxide/alumina) to avoid heat loss. Alumina does not interact with microwaves; therefore, it acts as insulator and microwaves can pass through it. The domestic microwave oven experimental setup is as shown in Fig. 1.

In the present experiment, various trials were carried out at a constant power of $900 \mathrm{~W}$, while varying the exposure time from 20 to $38 \mathrm{~min}$. The observations while doing the experiments are given in Table 2.

It is clear from Table 2 that melting and dilution of clad powder depends on the microwave exposure time. Consequently, the exposure time was found out to be $38 \mathrm{~min}$ and maintained during the cladding process with the cooling time of $12 \mathrm{~min}$ between the successive experiments. The details of the parameters of the experiment are given in Table 3.

\subsubsection{Wear test}

The wear test has been conducted using the standard tribometer as shown in Fig. 2. The tribometer measures the different quality such as wear rate, the coefficient of

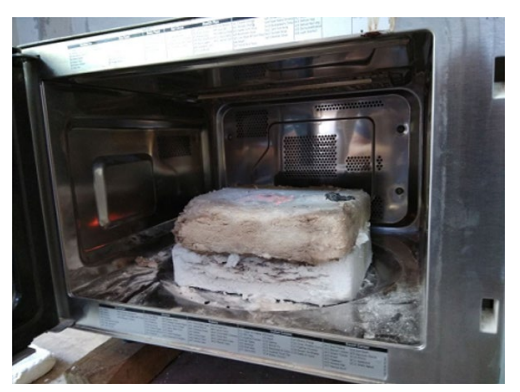

Fig. 1 Microwave cladding setup
Table 1 Chemical composition of substrate

\begin{tabular}{llllllll}
\hline Element & $\mathrm{Cr}$ & $\mathrm{Mn}$ & $\mathrm{C}$ & $\mathrm{Ni}$ & $\mathrm{Si}$ & $\mathrm{Mg}$ & $\mathrm{Fe}$ \\
\hline SS-420 & 13.69 & 1.2 & 0.28 & 0.58 & 0.65 & 0.04 & Bal. \\
\hline
\end{tabular}


Table 2 Observations from the experiment trials

\begin{tabular}{lll}
\hline Trial number & Exposure time $(\mathrm{min})$ & Observation \\
\hline 1 & 20 & No cladding observed \\
2 & 25 & Powder didn't melt \\
3 & 30 & Partially melted \\
4 & 33 & Powder melted but not enough metallurgical bond \\
5 & 38 & $\begin{array}{l}\text { Powder melted with a proper metallurgical bond } \\
\text { to the substrate }\end{array}$ \\
\hline
\end{tabular}

Table 3 Details of experiment

\begin{tabular}{ll}
\hline Parameter & Description \\
\hline Applicator mode & Make: LG Solar Dom \\
Power & $900 \mathrm{~W}$ \\
Frequency & $2.45 \mathrm{GHz}$ \\
Susceptor & Silicon carbide \\
Separator & Glass wool \\
Refractory material & Aluminium oxide \\
Exposure time & $2280 \mathrm{~s}$ \\
Average cooling time & $720 \mathrm{~s}$ \\
Substrate dimension & $14 \times 12 \times 5 \mathrm{~mm}$ \\
\hline
\end{tabular}

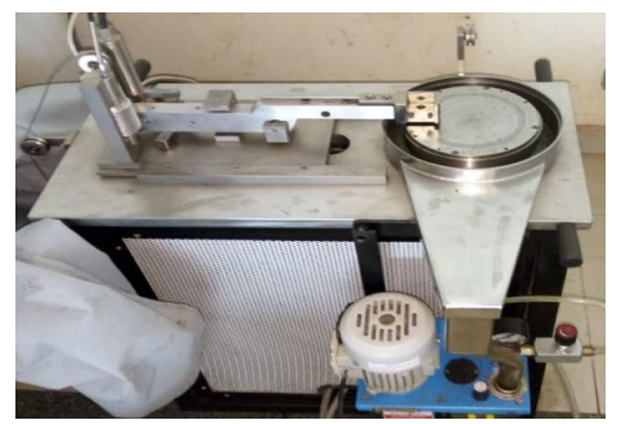

Fig. 2 Shows pin-on-disc type wear testing experimental setup

friction, etc., for the surface measurement. The tribometer used for this study is a pin-on-disc apparatus. Since the sample here is in a rectangular shape, it is welded using tungsten inert gas welding to the pin. The pin-on-disc apparatus specifications are given in Table 4 .

\subsubsection{Taguchi analysis}

The design of experiment method used in this study is based on Taguchi technique. It is used as an optimisation technique for design parameters. Because the unplanned experiments and trials are costly and time-consuming, hence the statistical analysis is used. Based on the literature survey, three control factors have been chosen. The selected control factors and levels considered are in Table 5. In the present study, the standard orthogonal
Table 4 Details of the wear testing apparatus

\begin{tabular}{ll}
\hline Disc size & $165 \times 8 \mathrm{~mm}$ \\
Normal load & $5-200 \mathrm{~N}$ \\
Rotational speed & $200-2000 \mathrm{RPM}$ \\
Wear track diameter & $140 \mathrm{~mm}$ or variable \\
Pin diameter & $6,8,10,12$ and $14 \mathrm{~mm}$ \\
Loading system & Using dead weight \\
\hline
\end{tabular}

Table 5 Experimental factors

\begin{tabular}{llll}
\hline Level & $\begin{array}{l}\text { SL-sliding dis- } \\
\text { tance }(\mathrm{m})\end{array}$ & $\begin{array}{l}\text { SS-sliding speed } \\
(\mathrm{m} / \mathrm{s})\end{array}$ & L-load $(\mathrm{N})$ \\
\hline 1 & 1000 & 2 & 20 \\
2 & 2000 & 4 & 30 \\
3 & 3000 & 6 & 40 \\
\hline
\end{tabular}

L9 array is considered. The experiments are conducted according to this array, and experimental data are generated. The mean response to the wear rate is found using the smaller is the better condition. Finally, the pin-on-disc wear rate has been analysed using ANOVA.

\section{Results and discussion}

The pin-on-disc wear test is experimentally carried out using the standard tribometer by Taguchi technique using L9 orthogonal array. The initial factors and levels are considered based on a literature survey. The experiment is conducted, and the data generated were analysed using Minitab 17 software tool.

\subsection{Statistical analysis}

The effect of each control factor (sliding speed SS, sliding distance $S D$, Load $L$ ) analysis was carried out with the response table for means using Minitab 17 software tool. The experimental wear results are given in Table 6 . Using the experimental results, ANOVA table is generated. By determining the ratio of two variances, the statistical 
significance is completed. This ratio is free from several possible alterations to the experimental observations. With the reference to Table 7, DF is a degree of freedom, which is representing the factor with less number of levels.

The model DF is a number of factors used to fit in the model. The higher the value of percentage contribution, the later its influence in the experimentation. Table 7 shows the ANOVA result for the clad samples. The analysis was carried using a confidence level of $95 \%$ with the error of 5. From the analysis, it is noted that all the control factors have an important role in the loss in mass of clad material. From Table 7, variance of the clad can be observed, with sliding distance (SD) (91.43\%) and load (L) (6.69\%) being the major factor influencing the mass loss and sliding speed (SS) $(0.27 \%)$ of less significance. It can be observed from the table, the $1.61 \%$ error is due to various factors such as machine error during the experiment. The average mass loss of clad substrate is $0.0167 \mathrm{~g}$. The error formed due to the difference in the average mass loss influenced the factor which varies during the experiment; hence, an error is controlling factor that confines the loss of mass of cladded material in the last column of Table 7.

\subsection{Control factor analysis}

The control factor analysis helps in identifying the influence of several factors controlling the experiment. The response table for mass loss of the developed clad is

Table 6 Experimental results of L-9 array

\begin{tabular}{lllll}
\hline S. no & SD & SS & L & Mass loss (g) \\
\hline 1 & 1000 & 2 & 20 & 0.0063 \\
2 & 1000 & 4 & 30 & 0.0100 \\
3 & 1000 & 6 & 40 & 0.0094 \\
4 & 2000 & 2 & 30 & 0.0131 \\
5 & 2000 & 4 & 40 & 0.0158 \\
6 & 2000 & 6 & 20 & 0.0096 \\
7 & 3000 & 2 & 40 & 0.0290 \\
8 & 3000 & 4 & 20 & 0.0244 \\
9 & 3000 & 6 & 30 & 0.0330 \\
\hline
\end{tabular}

shown in Table 8. It helps in analysing the control factors based on delta statistics. The delta statistics depend on the average value to the lowest value of an individual factor, and the delta ranks are assigned based on the delta value. Delta value is assigned according to the higher value to the lesser value. With the help of this process, more data can be acquired for examination and higher value plays important role in the mass loss of the surface.

The maximum delta value has a significant factor in the loss of mass. It is observed from Table 7 that the most significant factor for loss of surface mass was exerted by the sliding distance (SD) and load (L), respectively. The process parameters main effects plot is shown in Fig. 3. It is observed that the parameter closer to the horizontal axis of the respective plot has the less important results in the loss of mass on the surface. The parameter line which is more inclined from the horizontal line has a much more important effect on the loss of mass on both the surfaces. It is clear from the main effects plot that the sliding distance (SD) and load are the most significant factors than sliding speed (SS) which is the less important effect on mass loss of the surface. It is clear from ANOVA that wear is maximum at the high sliding distance $3000 \mathrm{~m} / \mathrm{s}$ compared to 2000 and $1000 \mathrm{~m} / \mathrm{s}$. The effect of the sliding distance was observed from the plot, as the distance increases the wear rate also increases in the range between 0.008567 and $0.028800 \mathrm{~g}$ of the clad sample. The second important factor is a load of which wear rate is between 0.013433 and $0.018067 \mathrm{~g}$. It is observed from the control factor that sliding speed is of less impact on the clad surface where the range of wear is between 0.016133 and $0.017333 \mathrm{~g}$.

Table 8 Response table

\begin{tabular}{llll}
\hline Level & \multicolumn{2}{l}{ Mass loss of clad samples } \\
\cline { 2 - 4 } & SD & SS & L \\
\hline 1 & 0.008567 & 0.016133 & 0.013433 \\
2 & 0.012833 & 0.016733 & 0.018700 \\
3 & 0.028800 & 0.017333 & 0.018067 \\
Delta & 0.020233 & 0.0012 & 0.005267 \\
Rank & 1 & 3 & 2 \\
\hline
\end{tabular}

Table 7 ANOVA of developed clad samples

\begin{tabular}{lllllcl}
\hline Level & df & SS & Adj SS & Adj MS & F-Value & $\begin{array}{c}\text { Percentage } \\
\text { of contribu- } \\
\text { tion }\end{array}$ \\
\hline SD & 2 & 0.000683 & 0.000683 & 0.000341 & 54.66 & 91.43 \\
SS & 2 & 0.000002 & 0.000002 & 0.000001 & 0.17 & 0.27 \\
L & 2 & 0.00005 & 0.00005 & 0.000025 & 3.97 & 6.69 \\
Error & 2 & 0.000012 & 0.000012 & 0.000006 & & 1.61 \\
Total & 8 & 0.000747 & 0.000747 & & & 100 \\
\hline
\end{tabular}




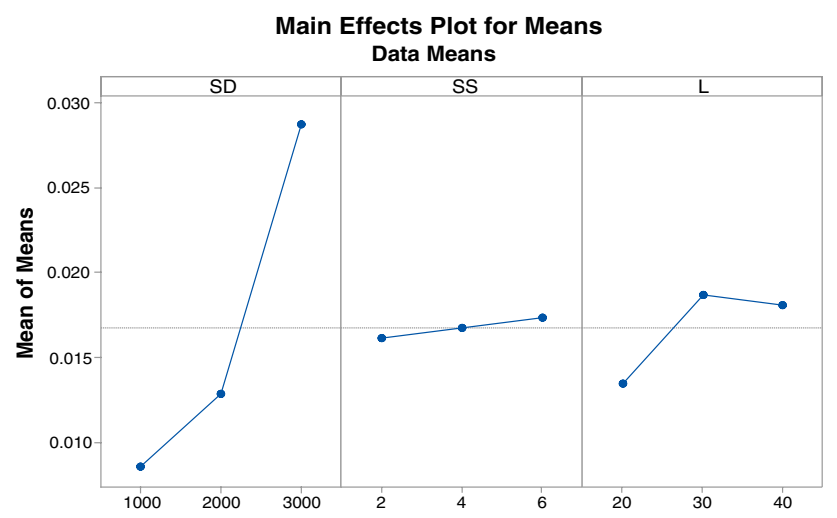

Fig. 3 Main effects plot for means WC-12Co-based clad

\subsection{Characteristics of sliding wear}

To understand the wear behaviour of the developed clad surface, fractography studies of the microwave clads were carried out through SEM as shown in Fig. 4. The material loss can be easily predicted with subsequent groves and craters. The wear of the reasonably brittle clads at an average speed is generally due to fatigueinduced material pull-out, that effects in formation of crater. However, at relatively lower sliding speed, the tribology of the mating surfaces is more rubbing; while, as a relatively increase in speed that leads to microcutting plays a more dominant role, as observed by the sharp wear marks and grooves from Fig. 4. It is also observed that at higher sliding speed, interaction of the mating surfaces exists for shorter period; therefore, the clad surface loss is due to sever plastic flow which results in shearing of the displaced material. Higher hardness effectively obstructs the crack propagation and interaction on the developed clad surface [16]. Therefore, it is clearly observed from Table 6 that the developed clad shows minimum wear rate, which is due to the improved surface hardness of developed clad surface.

\section{Conclusions}

The tungsten carbide with $12 \%$ cobalt-based powder clad was successfully developed on martensitic SS-420 steel through microwave energy. The clads were developed through domestic microwave oven of frequency $2.45 \mathrm{GHz}$ and $900 \mathrm{~W}$ power. The pin-on-disc wear study of the developed clad was studied using Taguchi orthogonal array $L 9$ technique. The individual factors and percentage of contribution of each factor are found out using ANOVA technique, and the following results are outlined.

- The developed composite calds are metallurgically bonded by partial melting of the substrate with full melting clad powder.

- It is clear from the main effects plot that the sliding distance (SD) and load are the most significant factors than sliding speed (SS) which is the less important effect on mass loss of the surface.

- The effect of the sliding distance was observed from the plot as the distance increases the wear rate also increases.

- The maximum wear rate was found to be in the range $0.008567 \mathrm{~g}$ to $0.028800 \mathrm{~g}$.

- It is observed from the control factor that sliding speed is of less impact on the clad surface where the range of wear is between 0.016133 and $0.017333 \mathrm{~g}$.
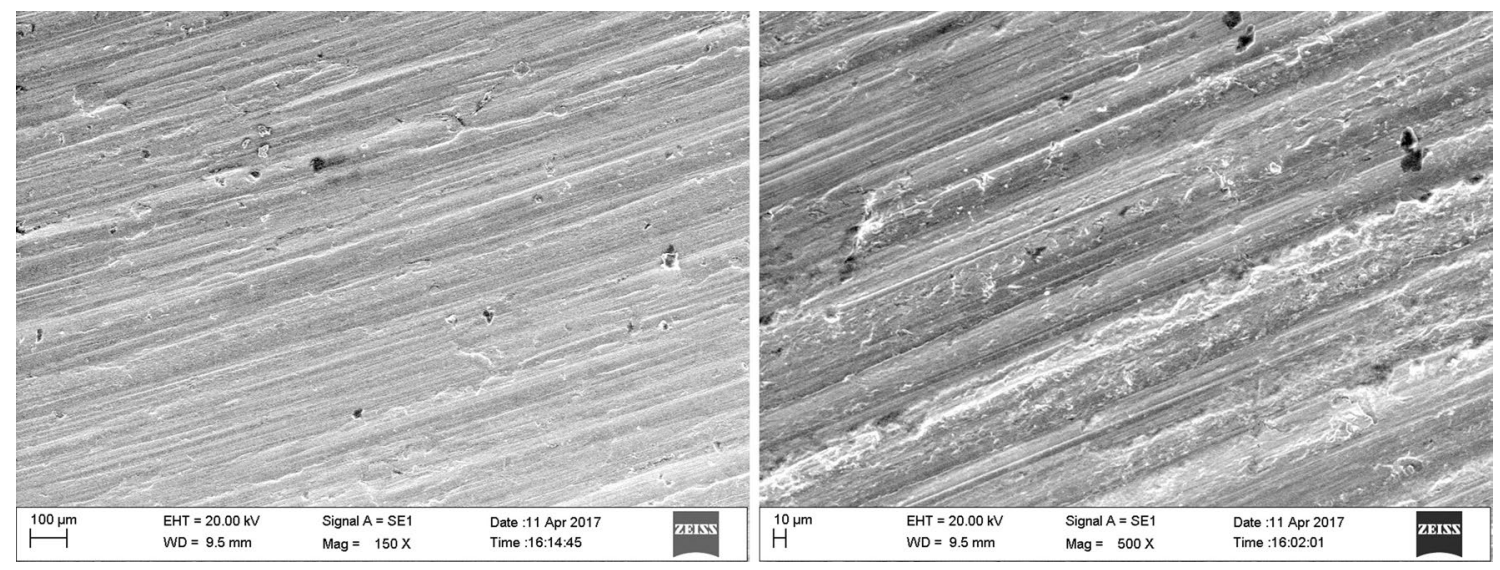

Fig. 4 SEM images of worn clad surfaces 


\section{Compliance with ethical standards}

Conflict of interest The authors declare that they have no conflict of interest.

\section{References}

1. Sharma AK, Aravindhan S, Krishnamurthy R (2001) Microwave glazing of alumina-titanium ceramic composite coatings. Mater Lett 50:295-301

2. Delregno GE, Mohan VR, Saha S (2005) Method of microwave processing ceramics and microwave hybrid heating system for same, US Patent 2005. Application no. WO2005027575 A3

3. Srinath MS, Hebbale AM (2017) Fuzzy prediction of slurry erosive behavior of cobalt based clad developed through microwave energy. Mater Today Proc 4:1804-1811

4. Zafar S, Sharma AK (2016) Abrasive and erosive wear behaviour of nanometric WC-12Co microwave clads. Wear 346-347:29-45

5. Gupta D, Sharma AK (2011) Development and microstructural characterization of microwave cladding on austenitic steel. Surf Coat Technol 205:5147-5155

6. Zhou S, Zeng X, Qianwu Hu, Huang Y (2008) Analysis of crack behavior for Ni-based WC composite coatings by laser cladding and crack-free realization. Appl Surf Sci 255:1646

7. Hebbale AM, Srinath MS (2016) Microstructural investigation of Ni based cladding developed on austenitic SS-304 through microwave irradiation. J Mater Res Technol 5:293-301

8. Hebbale AM, Srinath MS (2017) Taguchi analysis on erosive wear behavior of cobalt based microwave cladding on stainless steel AISI-420. Measurement 99:98-107
9. Zafar S, Sharma AK (2015) Dry sliding wear performance of nanostructured WC-12Co deposited through microwave cladding. Tribol Int 91:14-22

10. Gajjala SY, Unkuleb AJ, Gajjalc PS (2016) Taguchi technique for dry sliding wear behavior of PEEK composite materials. Procedings 5:950-957

11. Taguchi G (1986) Introduction to quality engineering: designing quality into products and processes, the organization, Tokyo

12. Bushroa AR, Masjuki HH, Muhamad MR, Beake BD (2011) Optimized scratch adhesion for TiSiN coatings deposited by a combination of DC \& RF sputtering. Surf Coat Technol 206:1837-1844

13. Zafar S, Sharma AK (2016) Structure-property correlations in nanostructured WC-12Co microwave clad. Appl Surf Sci 370:92-101

14. Leonelli C, Veronesi P, Denti L, Gatto A, Iuliano L (2008) Microwave assisted sintering of green metal parts. J Mater Process Technol 205:489

15. Oghbaei Morteza, Mirzaee Omid (2010) Microwave versus conventional sintering: a review of fundamentals, advantages and applications. J Alloys Compd 494:175

16. Hebbale AM, Srinath MS (2018) Microstructural studies of cobalt based microwave clad developed on martensitic stainless steel (AISI-420). Trans Indian Inst Met 71(3):737-743

Publisher's Note Springer Nature remains neutral with regard to jurisdictional claims in published maps and institutional affiliations. 